\title{
Analysis and Design of a Project Portfolio Management System
}

\author{
Driss El HANNACH ${ }^{1}$, Rabia MARGHOUBI ${ }^{2}$, Zineb El AKKAOUI ${ }^{3} \&$ Mohamed DAHCHOUR $^{4}$ \\ ${ }^{1}$ National Institute of Posts and Telecommunications, Smart, Embedded, Enterprise and Distributed Systems, \\ (SEEDS) Team, Allal Al Fassi Avenue, Rabat, Morocco \\ Correspondence: Driss El HANNACH, National Institute of Posts and Telecommunications, Rabat, Morocco.
}

Received: April 14, 2019

doi:10.5539/cis.v12n3p42

\author{
Accepted: May 7, $2019 \quad$ Online Published: July 25, 2019 \\ URL: https://doi.org/10.5539/cis.v12n3p42
}

\begin{abstract}
The paramount importance of project portfolios for business drives managers to search for highly efficient support tools to overcome complex challenges of their management. A major tradeoff is to acquire tools able to produce a convenient portfolio project prioritization process, on which business investments are decided. However, by using existing Project Portfolio Management Systems (PPMS), many concurrent projects in a portfolio are usually prioritized and planned in the upstream life-cycle phases according to financial criteria, and overlooking the portfolio alignment to enterprise strategies and the availability of resources, although their importance. In this paper, we propose a conceptual formalization of PPMS with respect to a double portfolio prioritization process that performs two levels of selections according to both: i.) Strategy alignment, including returns on investment, size, and total cost; and ii.) Execution capability, as the organization should be able to manage and deliver the selected projects' outcomes. The advantage of our PPMS framework is twofold. First, it is useful to be customized by designers to fit organization needs. Second it is built with respect to the double prioritization phase process, as an end-to-end process that guarantees optimal portfolios generation. Further, the proposed PPMS system and its identified functionalities are validated through an implementation of a prototype tool.
\end{abstract}

Keywords: model-driven development, project portfolio management system, project portfolio management system process, analysis and design, project portfolio prioritization and optimization

\section{Introduction}

As organizations reach higher levels of maturity in individual project management, they focus on their collective management as a portfolio of projects. This transition seems to occur when they realize that projects are investments and not expenses, thus requiring alignment with organizational goals and creating value for the organization's owners and other stakeholders. Collective management of project investments brings coherence to the implementation of strategic and operational initiatives and helps the organization to create long-term sustainable value. In project management, the enterprises should not only do projects right to meet the needs of time, budget and scope, but also to align them with strategic objectives (Mantel et al., 2011; Bible et al., 2011; Jian WEN, 2010).

Actually, a project portfolio is generally used to refer a collection of programs, projects or operations that are managed as a group to achieve strategic objectives (PMI, 2012). Categorization, evaluation and prioritization of the project portfolio are essential processes for project portfolio management and play an important role in achieving the organization's strategic objectives. Assuming this, we established, in a previous work, a state of the art about portfolio prioritization approaches and proposes a twofold approach, taking into account both strategic and operational objectives of the organization (Driss et al., 2016a).

In many cases (Ricardo et al., 2017; Driss el al., 2018; Arisa et al., 2015), the only decisions criteria taken into account in portfolio prioritization are financial, such as the Return on Investment (ROI) and capital rationing. The profit-based nature of these criteria, applied generally at individual project level, leads most organizations to adopt them (Augustin \& Constanta-Nicoleta, 2014). In the other cases, the decision-making process is always based on experience and subjectivity and depends on the profile of managers (Ricardo et al., 2017; Romeo and Marivic, 2010). Then, the choice of experts greatly affects the quality of projects prioritization. We developed an approach (Driss et al., 2016b) to make the decision of portfolio prioritization less subjective based on information entropy and a hybrid approach. The approach is taking into account the imprecision of data and the 
uncertainty of the judgments of assessor's when evaluating organization projects according to both financial and organizational criteria. (Augustin \& Constanta-Nicoleta, 2014) argued that the general execution of projects oriented organizations depends not just on the fruitful usage of a couple of extensive, complex activities that they are actualizing yet rather on how the whole arrangement of undertakings is overseen.

Today's business dynamics require considering another major criteria when building the project portfolio, which is the availability of resources. Project portfolio prioritization processes based on qualitative and quantitative criteria were used for resources allocation (Ghasemzadeh \& Archer, 2000; Caballero \& Schmidt, 2014). Decision-making to justify the resources allocation under capital rationing was discussed in (Romeo and Marivic, 2010). However, to the best of our knowledge, no current approach considers the two main aspects simultaneously, including financial, strategic and resources availability in building the project portfolio. This is mainly due to the fact that resource availability is not precisely known at the early stage of portfolio construction (Ou Liu et al., 2016). Thus, a first contribution of this work is a double-phase prioritization process, called PPMS, that allows building a project portfolio. It starts by a pre-selection phase based on strategic, time, budget, and scope criteria (1st prioritization) and ends by a refined selection phase (2nd prioritization) where selected projects are composed in concurrent potential portfolios, and the optimal one is selected based on the availability of resources, once the information is accessible.

Additionally, project portfolio process is carried out by project management systems (White \& Fortune, 2002). Their nature has changed considerably in recent decades; yet, they are still in development and hardly support prioritization solutions (Ahlemann \& Backhaus, 2006; Sajad \& Sadiq, 2016). Research proposals (Dorndorf et al., 2000; Hartmann, 2002; Romeo \& Marivic, 2010) mostly consider prioritization as an operational research problem and propose algorithms to enhance project management systems with prioritization features. Few attempts are tackling the development assistance for project management systems. For instance, (Kurbel, 1994; Schulz et al., 1996) are proposed a prototypes that are limited to testing new features such as project scheduling, project threshold and project activity.

At the same time, specific challenges in project management increase the complexity in real-world decision-making and lead to heuristic approaches to assign projects into portfolio instead of dedicated systems (Augustin \& Constanta-Nicoleta, 2014). Challenges are such the growing number of business processes to considering, the number of projects and the total restricted grant funding provided by the organization. As a consequence, a survey of experts indicates that only in $20 \%$ of cases organizations have project management systems that support programs and portfolios. In contrast, about $99 \%$ of organizations use such systems for planning and time management (Frederik, 2009).

The study of a set of current well-known project management systems ${ }^{1}$, e.g. (Demetrios et al., 2010; Jehad, 2011), shows that they are very expensive in terms of user licenses, deployment, maintenance and upgrades. They only deal with projects individually and not in a project portfolio context. From a software development point of view, the source code of these systems as well as their design is not open. Therefore, organizations become dependent on these proprietary tools. In terms of taking care of stakeholders, these systems do not take into account all the actors of the company. On the other hand, project management standards such as ISO21504 and PMBOK serve only to guide decision-makers in the topic of project portfolio prioritization but not as a concrete framework.

As a matter of fact, there is unanimity neither on methodologies, nor on systems implementing these methodologies for project portfolio management. Also, they are almost costly and could not be personalized to the organization needs and specifications. Therefore, our second and main contribution in this work is a conceptual framework for developing project portfolio management system. Concretely, we propose a novel vendor-independent metamodel providing the main entities carried out by such systems together with major functionalities, exhibited through use cases and activity diagram.

At the same time, by using the Model-Driven Development (MDD), an approach to software development by the $\mathrm{OMG}^{2}$, a translation of the conceptual framework to a logical model and code generation are straightforward. As a proof of concept, we show how we were able to implement this framework as a project portfolio management prototype tool. The rationale behind our proposal is twofold: (i.) such framework is useful to be customized by designers to fit organization needs; (ii.) building PPMS upon this framework are based on a double prioritization phase process, as an end-to-end process able to generate optimal project portfolio.

\footnotetext{
${ }^{1}$ http://www.microsoft.com/project/en/gb/project-pro-2010-new-features.aspx accessed on January 5, 2019.

${ }^{2}$ https://www.mendix.com/model-driven-development/ accessed on March 18, 2019.
} 
The outline of this work is structured as follows. Section 2 reviews the related work in project management systems. Section 3 proposes and describes the Project Portfolio Management System Process (PPMSP). Section 4 presents formal conception of the PPMS. Section 5 describes the modeling of the PPMS. Section 6 implements the prototype of the system. Finally, Section 7 presents conclusion and future work.

\section{Related Work}

The process of project portfolio prioritization takes into consideration the evaluation of a group of existing new projects in way to execute them in order to achieve strategic objectives (Mantel et al., 2011). Project portfolio assessment is a repetitive work that finds the maximum possible added value for organizations (Ghasemzadeh \& Archer, 2000).

A good project takes not only his executing rightly but such as doing the appropriate project (Bible et al., 2011). For that, portfolio prioritization approaches have a substantial part in portfolio management. However, there are many approaches, and there is no consensus on the best methodology (Archer \& Ghasemzadeh, 2004). Then, organizations use the better methodology that takes into account their organizational project management. (Mantel et al., 2011) divide also the project selection methods in two categories: nonnumeric and numeric.

\subsection{Non-numeric Prioritization Methods}

Qualitative prioritization models exist in the large organizations since they are easy to handle by the responsible. They include mostly comparative approaches such as Quick sort (Q-sort) and Analytical Hierarchy Process (AHP) (Mantel et al., 2011; Saaty, 2008). The AHP support stakeholders to classify and select the good projects based on qualitative and multiple comparisons.

A Q-sort is another non-numeric way to handle the prioritization task. In the first place, it separate the undertakings into three subsets utilizing whatever criteria that chiefs have picked or been told to utilize. If there are more individuals, separate them into two others subsets. Then, we repeat subdividing operation until no subset has more than seven or eight projects. Then, we prioritize the alternatives in each subset and we arrange the subsets in order to ranking the entire list of projects.

\subsection{Numeric Prioritization Methods}

Project proposals are selected with Numerical aspect (Caballero \& Schmidt, 2014) tacking into consideration both some quantitative and qualitative criteria such as:

- Financial point of view as Discounted Cash Flow (DCF), Net Present Value (NPV), Internal Rate of Return (IRR) and pay-back period. (Blocher et al., 2010) state that the most organizations use these models to prioritize projects.

- The weighted scoring models take a lot of parameters that contain their importance weight. Projects are scored with respect each criterion weight (Mantel et al., 2011). (Archer and Ghasemzadeh, 2004) claimed that thse methods are simple to use, but they have some limitations.

- Operational research models based on optimization algorithms are another way to select an optimal portfolio called Decision Making Unit (DMU) that produces the maximum profit. (Archer \& Ghasemzadeh, 2004) claimed that these kinds of uses are difficult to implement and need a lot of data sources.

Several challenges make difficult the correct choice of project portfolio management system, such as: (1) Lack of information, unreliable cost data, time to completion, availabilities of resource, and benefits of projects (Cooper et al., 2001; Rădulescu et al., 2001); (2) The annual plan review carried out by organizations, which automatically eliminate opportunities for new project proposals originating from different sources (Lu et al., 1999; Kendall \& Rollins, 2003); (3) Dynamic change, particularly in large organizations, which is mandatory to create the dynamic capabilities needed to survive and outperform competitors (Chrusciel \& Field, 2006; Walker et al., 2007); (4) The management difficulties in large organizations that have many business units, as each business unit has its own list of priority and preferences. In addition, project portfolio selection is not always rational, but rather is based by the human factor since lobbying activities (Yelin, 2005).

In the literature, there are many software tools for project management (Sajad \& Sadiq, 2016). These software tools have advantage and disadvantage. The advantage of these tools is that they meet the needs of portfolio management, including collaborative work. Nevertheless, the lack of such solutions is that they are very cumbersome to put in place, and they require having already a certain level of maturity in the governance of the projects. They also require a thorough review of internal processes to adapt to those imposed by these tools.

Table 1 shows a comparative study to highlight the value of our approach to designing the tool for prioritizing and optimizing the project portfolio. Our proposed PPMS have the advantage of integrating the management 
module relating to the prioritization of the portfolio. In addition, it takes into account the constraints related to the allocation of available resources (human, capital, equipment ... etc.). The strong point offered by these PPMS, is that it makes it possible to take into consideration the methods of prioritization and the criteria associated with the projects in a flexible way. Thus, the systems generating criteria and prioritization methods are proposed in our design analysis. In addition, this paper shows the conceptual model based on UML diagrams that model the prioritized and optimal project portfolio. Finally, we validate the PPMS with an implementation of the prototype that contains a set of functionalities that take into consideration the double prioritization steps.

Table 1. A comparative study of prioritizing project portfolio tools

\begin{tabular}{|c|c|c|c|c|c|c|c|}
\hline $\begin{array}{c}\text { Project } \\
\text { Management } \\
\text { Softwares and } \\
\text { standards }\end{array}$ & Stakeholders & $\begin{array}{c}\text { Project } \\
\text { performance } \\
\text { criteria }\end{array}$ & $\begin{array}{l}\text { Prioritization } \\
\text { methods }\end{array}$ & Resources & Process & Design & Environment \\
\hline Primavera $^{\mathrm{I}}$ & $\begin{array}{l}\text { Project } \\
\text { Manager }\end{array}$ & $\begin{array}{l}\text { The user can } \\
\text { define the } \\
\text { criteria }\end{array}$ & $\begin{array}{c}\text { Identify, } \\
\text { categorize and } \\
\text { prioritize } \\
\text { potential risks } \\
\text { only }\end{array}$ & $\begin{array}{l}\text { Personal, } \\
\text { Equipment }\end{array}$ & $\begin{array}{l}\text { Activity } \\
\text { operation }\end{array}$ & $\begin{array}{l}\text { Not } \\
\text { public }\end{array}$ & internal \\
\hline MS Project $^{2}$ & $\begin{array}{l}\text {-Project } \\
\text { Manager } \\
\text {-Team } \\
\text { member } \\
\text {-Manager } \\
\end{array}$ & N/D & N/D & $\begin{array}{l}\text { People, } \\
\text { Equipment }\end{array}$ & $\begin{array}{l}\text { Monitor the } \\
\text { project's } \\
\text { progress }\end{array}$ & $\begin{array}{l}\text { Not } \\
\text { public }\end{array}$ & $\begin{array}{l}\text { PC-based } \\
\text { software }\end{array}$ \\
\hline dotProject $^{3}$ & $\begin{array}{l}\text { Project } \\
\text { Manager } \\
\end{array}$ & N/D & N/D & N/D & Task tracker & $\begin{array}{l}\text { Not } \\
\text { public }\end{array}$ & $\begin{array}{l}\text { Web } \\
\text { application }\end{array}$ \\
\hline Assembla $^{4}$ & $\begin{array}{l}\text { Team } \\
\text { member }\end{array}$ & N/D & N/D & N/D & $\begin{array}{l}\text { Perform project } \\
\text { activities and } \\
\text { task tracking }\end{array}$ & $\begin{array}{c}\text { Not } \\
\text { public }\end{array}$ & $\begin{array}{l}\text { Web } \\
\text { application }\end{array}$ \\
\hline Redmine $^{5}$ & $\begin{array}{l}\text { Team } \\
\text { member }\end{array}$ & N/D & N/D & N/D & \begin{tabular}{|l|} 
Task \\
identification
\end{tabular} & $\begin{array}{l}\text { Not } \\
\text { public }\end{array}$ & $\begin{array}{l}\text { Web } \\
\text { application }\end{array}$ \\
\hline Iso21504 & $\begin{array}{l}\text {-Steering } \\
\text { committee } \\
\text {-Project } \\
\text { Manager } \\
\text {-Project team } \\
\text {-Senior } \\
\text { Manager }\end{array}$ & $\begin{array}{l}\text { Guidance on } \\
\text { use criteria }\end{array}$ & $\begin{array}{l}\text { Guidance on } \\
\text { prioritization }\end{array}$ & $\begin{array}{l}\text { Guidance on } \\
\text { resource } \\
\text { allocation }\end{array}$ & $\begin{array}{l}\text {-Define portfolio } \\
\text {-Identify } \\
\text { components } \\
\text {-Assess } \\
\text { components } \\
\text {-Portfolio } \\
\text { alignment } \\
\text {-Portfolio } \\
\text { performance } \\
\text {-Portfolio } \\
\text { Optimization }\end{array}$ & $\mathrm{N} / \mathrm{D}$ & Internal \\
\hline $\mathrm{PMBOK}^{\prime}$ & $\begin{array}{l}\text {-Steering } \\
\text { committee } \\
\text {-Project } \\
\text { Manager } \\
\text {-Project team } \\
\text {-Portfolio } \\
\text { Manager }\end{array}$ & $\begin{array}{c}\text { Define } \\
\text { activities }\end{array}$ & $\begin{array}{l}\text { Sequence } \\
\text { activities }\end{array}$ & $\begin{array}{c}\text { Activity } \\
\text { resource } \\
\text { management }\end{array}$ & \begin{tabular}{|l|}
-Project going \\
-Project plan \\
-Project \\
execution \\
-Project \\
monitoring and \\
mastery \\
-Project stop
\end{tabular} & N/D & internal \\
\hline
\end{tabular}

${ }^{1}$ (Demetrios et al, 2010)

2 (http://www.microsoft.com/project/en/gb/project-pro-2010-new-features.aspx accessed on January 5, 2019; Jehad, 2011)

3 (http://www.dotproject.net accessed on January 5, 2019; Christiane et al., 2009 ; Luyin et al., 2010)

${ }^{4}$ (Juan et al., 2011 ; http://www.computingportal.org/node/9585 accessed on January 5, 2019)

${ }_{5}^{5}$ (Christelle, 2011; Hasliza et al., 2011 ; http://www.redmine.org/projects/redmine/wiki/Featues accessed on January 5, 2019)

${ }^{6}$ (ISO 21504, 2015)

7 (PMBOK® Guide Sixth Edition, 2017) 
In the next section, we will present our project portfolio prioritization and optimization process. It's important for the implementation of our PPMS.

\section{Project Portfolio Management System Process (PPMSP)}

The PPMS based on both prioritization and optimization methods can be used during the enterprise prioritization process. The adoption of our PPMSP is a key factor for the implementation of our system. The Project Management Institute (Project Management Institute, 2012) presents a standard framework for project portfolio management that identifies, categorizes, evaluates, selects, prioritizes and balances the project portfolio. (Bible et al., 2011) have built a detailed project portfolio management (PPM) framework with a Pre-assessment stage and a selection stage. In the selection phase, the candidate projects are selected according to specific criteria, for example, the results of the profitability analysis. The selection phase incorporates the evaluation of the favorable parts of the projects, trailed by the selection both of the initial and optimal portfolio. (Archer \& Ghasemzadeh, 1999) proposed a general framework for project selection taking into account the full life cycle of projects. The process that supports our PPMS is depicted in Figure 1 and it consists of three main phases namely: Evaluation, Planification and Monitoring.

\subsection{Evaluation}

A lot of candidate projects are proposed. These activities can come from client requirements, legal/ecological prerequisites, the development of new products, and so on. After that, candidate projects are reviewed if they are connected to something like one key objective of the organization. Any project that does not meet this criterion should be removed. Next, a business case is produced for the potential projects with the reason for characterizing some principal attributes of projects such as NPV, costs, duration, risk level, etc. We consider additionally the assessment of various criteria that are critical achievement factor for any project and incorporate the economic and technical feasibility and sustainability. The economic evaluation guarantees that project is profitable for the organization. Technical feasibility ensures the organization can obtain the technology to undertake the project. The sustainability assessment includes ecological and social impact.

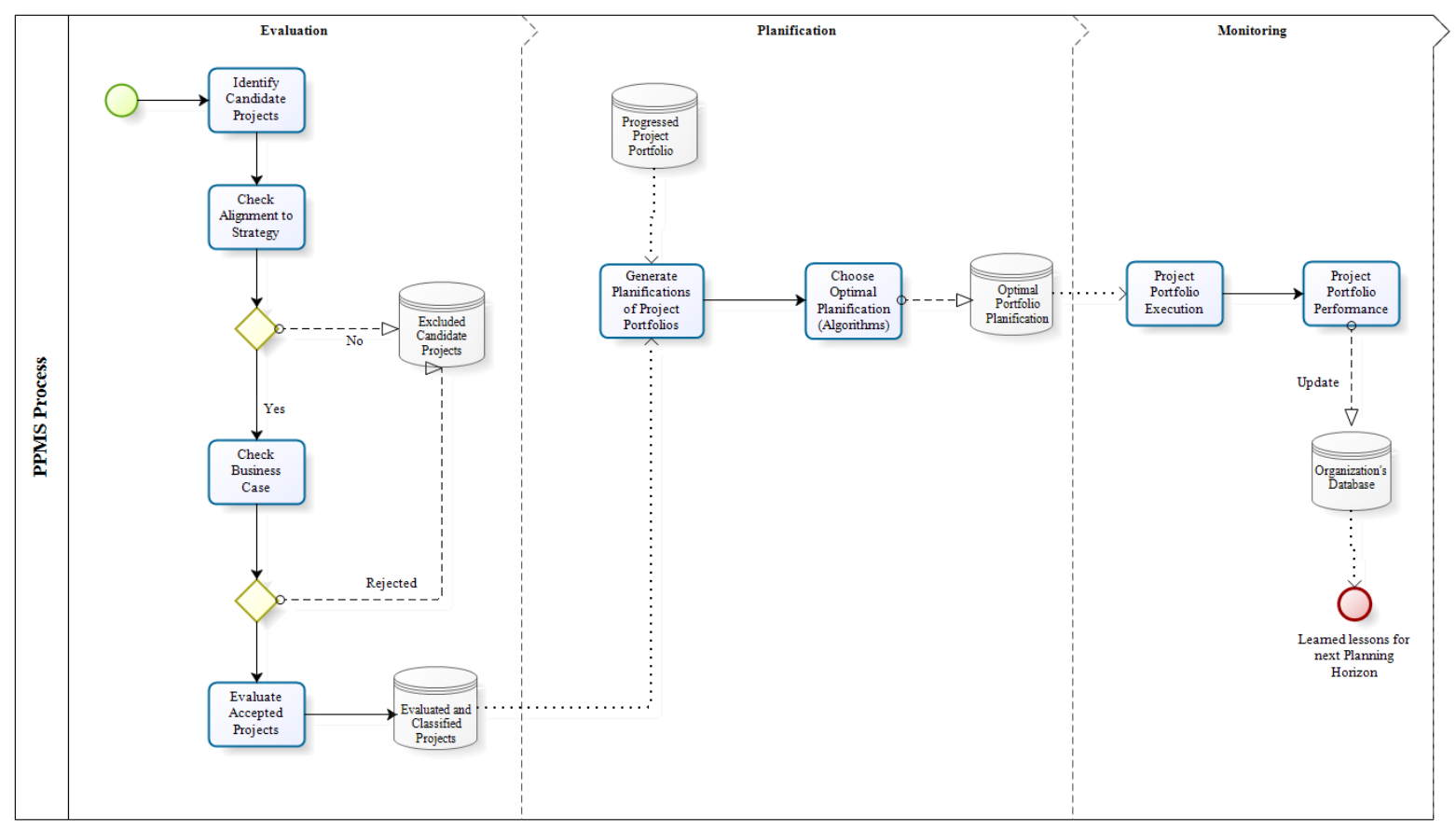

Figure 1. Project Portfolio Management System Process by using Bizagi ${ }^{1}$

\footnotetext{
${ }^{1}$ Bizagi Process Modeler Version 2.7.0.2 May 6, 2014.
} 


\subsection{Planification}

It consists in two steps (prioritization and optimization) because the visibility on available resources is not sufficient when creating the portfolio through the selection of projects under financial and other criteria. And then refine that selection once the visibility on available resources becomes better. So, an optimal solution is found and decision-makers can make adjustment in the final selected portfolio.

\subsection{Monitoring}

It includes the activities required to develop all deliverables of projects according to the scope, time and cost approved. And finally, it should include portfolio performance assessment and verification that goals were meet. It gives valuable information and learned lessons to the organization.

\section{PPMS Specification}

During the development of this section, we collect the information needed to develop an analysis and design approach for our future PPMS tool. For this, an in-depth survey was conducted through the study of research work carried out in the field of project management. We then discuss the project environment of our system.

The objectives of companies and organizations are on the one hand the satisfaction of its customers through services meeting their expectations and realized in the budgets and the deadlines, and on the other hand the optimization of the resources so that the company can carry out its work in a profitable way. Due to the fact that the resources are small and the manpower limited, the project portfolio can't be managed by a person dedicated to this role. This implies a high risk of drift if there is no well-managed project portfolio management system that facilitates communication between different actors.

\subsection{Study Environment and Genesis of Projects}

One of the crucial management issues within organizations is the process of building the project portfolio. Indeed, the project portfolio is the culmination of a very complex process that originates from the generation of project ideas and, finally, the insertion of selected ideas (after prioritization and planning) into the range of projects. This requires a number of steps. These steps are not necessarily the same for organizations: it depends on how decision-makers want to organize the process, according to the objectives to be achieved, or according to the technical specifications of the products or services. Indeed, organizations manage two types of projects: projects for internal use and projects in partnership with other companies. Internal projects (the most numerous and vital for organizations) are generally the projects needed for business continuity, small projects, marketing communications projects, IT projects and those related to investments in infrastructure. The sources of innovation in organizations are of two kinds: external sources and internal sources.

\subsubsection{External Sources}

Suppliers and contractors. Business leaders approach these external legal entities to learn more about the evolution of technologies related to their areas of activity. In this context of information exchange, interactions benefit businesses and enable them to innovate and better meet the needs of customers.

Experts and consultants. They are physical persons or corporations who are more familiar with the behavior of the clients of the organizations. Generally, the entity responsible for the strategic development of the company seizes them to make the technological watch in the world. It is an information process characterized by some monitoring of the evolution of practices outside the organization. The goal is to predict as much as possible what could happen in the short, medium or long term, or what would become of a particular technology. This allows reactivity consistent with the current or future change.

Customers. They constitute the consumer market and are classified in two categories: residential customers (physical persons) and business customers (legal persons). Business customers represent a market segment comprising SMEs (Small and Medium-sized Enterprises) as well as LEs (Large Enterprises). These clients will have to be placed at the center of innovation strategies because the projects will have to respond to their specific preferences. It is in this vein that these clients will participate in the evaluation and prioritization of the organization's projects. It is also through their opinions that we find certain ideas of projects and innovation. It is the customers' opinions that drive the organization to ask consultants to trigger technology watch, and suppliers to develop a new technology. It is in this perspective that the organization takes their needs into account during the project prioritization process.

The competitive market. Considered as the external environment of the company, it arouses the interest of the managers, the needs of the customers, the creativity of the entrepreneurs and / or suppliers and especially of those who operate in the same sector of activities. This drives the organization to innovate in order to keep its 
customers and hold the monopoly of the market.

The partnership. The external environment of the company is often threatened by competition. To cope with this, the organization uses partnership (strategic decision-making means) thus allowing the generation of project ideas through exchanges.

The expansion of the territory. To adapt to the new realities of the market, the company will have to consider the territorial expansion through the projects of creation and implantation of the subsidiaries, and the projects of reorganization to improve the quality and the diversification of the products and / or the services. The idea or need to take ownership of a given territory generates new project ideas and fosters innovation.

\subsubsection{Internal Sources}

The management team of the company. It is composed of the president of the organization and the vice-presidents placed at the head of the poles (marketing, sales, strategy, finance, administration ...). It is usually these authorities who are the promoters of the projects. They can, depending on the case, be entered by the PMO (Project Management Office) for approval or rejection of a project idea.

The department heads. To carry out their needs, they formulate a certain number of projects. Depending on the case, they can proceed with the evaluation and / or prioritization.

Business directions. They are led by diversified business line managers where business people (analysts, supervisors, and employees) who build on their experiences, formulate project ideas. Users of the project portfolio management system report to these departments, who are responsible for providing products and / or services to clients. Their opinions on the prioritization of certain projects are necessary to the extent that their expertise makes it possible to bring a better judgment on the complexity of certain projects related to the customer service activities.

The strategic development component. It is a generally "ad-hoc" structure whose number of members is reduced. She is responsible for producing the company's strategic plan to guide actions over the next five years. This plan will be the preferred tool for the evaluation and prioritization of projects by the PMO.

PMO. According to the companies, the PMO manages two types of projects: the specific projects of the finance sector and the projects of the business areas of the company. Among the PMO's competencies is the role of prioritizing projects on the basis of the data provided by the promoters. It applies methods and uses contextualized criteria to achieve strategic objectives while meeting the needs of users. He must always seek a consensus between the actors. Its power of approval of project ideas is at two levels: the first for projects requiring a lower investment, it has the power of final decision of prioritization and rejection. The second for projects requiring a very large investment, approval of the steering committee is essential. The PMO works in collaboration with the Information Systems Directorate (ISD).

The executive committee. The steering committee is a multidisciplinary "ad-hoc" team created and assembled to decide on the prioritization of very important investment projects. He may be required to obtain the agreement of the project vice-president.

\section{PPMS Modeling}

Information systems (IS) are socio-economic systems that include software, hardware and the surrounding organizational system. Models play an important role in the design and implementation of these information systems (Frederik, 2009). Depending on the stage or level of IS design and implementation, three different types of information models can be distinguished: 1) conceptual models that help document, analyze, and understand the functional requirements that an IS must meet. These models do not take into account the technical aspects and focus only on the problem to be solved and / or on the processes to be supported. There are the conceptual models that will be treated in this work, 2) conversely; design models specify the overall architecture of the information system by detailing the description of the most important building blocks called components. However, such technical components are not discussed in this article, and 3) finally, the implementation models depend on the use of specific technologies and are closely related to the programming of software and frameworks.

In general, information models describe the static or dynamic aspects of information systems. Therefore, models are distinguished as those with information structures, i.e. data structures (data models), and those with information processes (process models). In a nut-shell: data models lead to database design, while process models typically serve as the basis for programming functionality.

Several graphical languages are available for IS modeling. One of the most widely used is the Unified Modeling 
Language (UML) (Object Management, 2005). UML class diagrams allowed for data modeling while activity diagrams are used for process modeling. The design and implementation of information systems should be viewed as a construction process and a subject of design science that explores how researchers can build high-quality artifacts that are good solutions to practical problems (Winter, 2006; Hevner et al., 2004).

The design part is the most delicate part. Indeed, from the functional needs we have identified the use cases diagram; then we proposed to define the class diagram. Finally, we modeled the activity diagram. In order to model the different diagrams we used Enterprise Architect software version 7.5, published by Sparx Systems. Enterprise Architect covers all aspects of the development cycle from requirement management to design phases.

The use cases are expressed from the needs identified below, containing all the actions to be performed by the system, in response to the actions of the actors. We present in Figure 2, the use cases diagram to associate the needs of the system with their stakeholders.

Functional requirements or functional needs of end users express functionalities of the PPMS. These are needs of the application and are intended to identify system's use cases. The actors who interact with the system have different roles. The Project Portfolio Manager is responsible of Portfolio. The database of resources gathers all data concerning resources (financial, material, human ...) and the Resource Manager is responsible for resource management and assignment. As for The Executive Director, he set up and monitors strategic objectives. The criteria generator system is the repository of criteria and sub-criteria. But the tools generator system is the repository of tools prioritization. Finally, the administrator is responsible for authorization management.

The portfolio is defined by its scope that several criteria are combined by associating organization (job, function, product, and market), geography (region, country, and continent) and accounting (OPEX: operational expenditure and CAPEX: capital expenditure). Then, offensive issues are considered as strategic alignment, arbitration decisions, coherence of resource management information and finally communication that providing reporting means to decision-makers to ensure the proper use of resources and the traceability of decisions. Furthermore, defensive issues are taking into account to break inconsistencies since "first come, first served" resource allocation and a high project requests that exceed the company's capacity.

The repository construction is important to build portfolios and its update is the basis of the system. So, it contains catalogs, databases ... etc. There are three ways to consider and through their combinations, we can define project life cycle, nature of financial commitments and extent in the organization.

For measuring gains from project prioritization, the system will have to measure gains through a comparison between current and future portfolio, based on indicators such as portfolio success rate (number of successful projects / number of projects launched), mortality (number of failed projects / number of projects launched), Portfolio value rate (realized value / expected value), total risk or average risk level, gap between effective delay and expected time, resource utilization rate, strategic coverage coefficient and coverage coefficient by domain (job, function, type of project ...). 


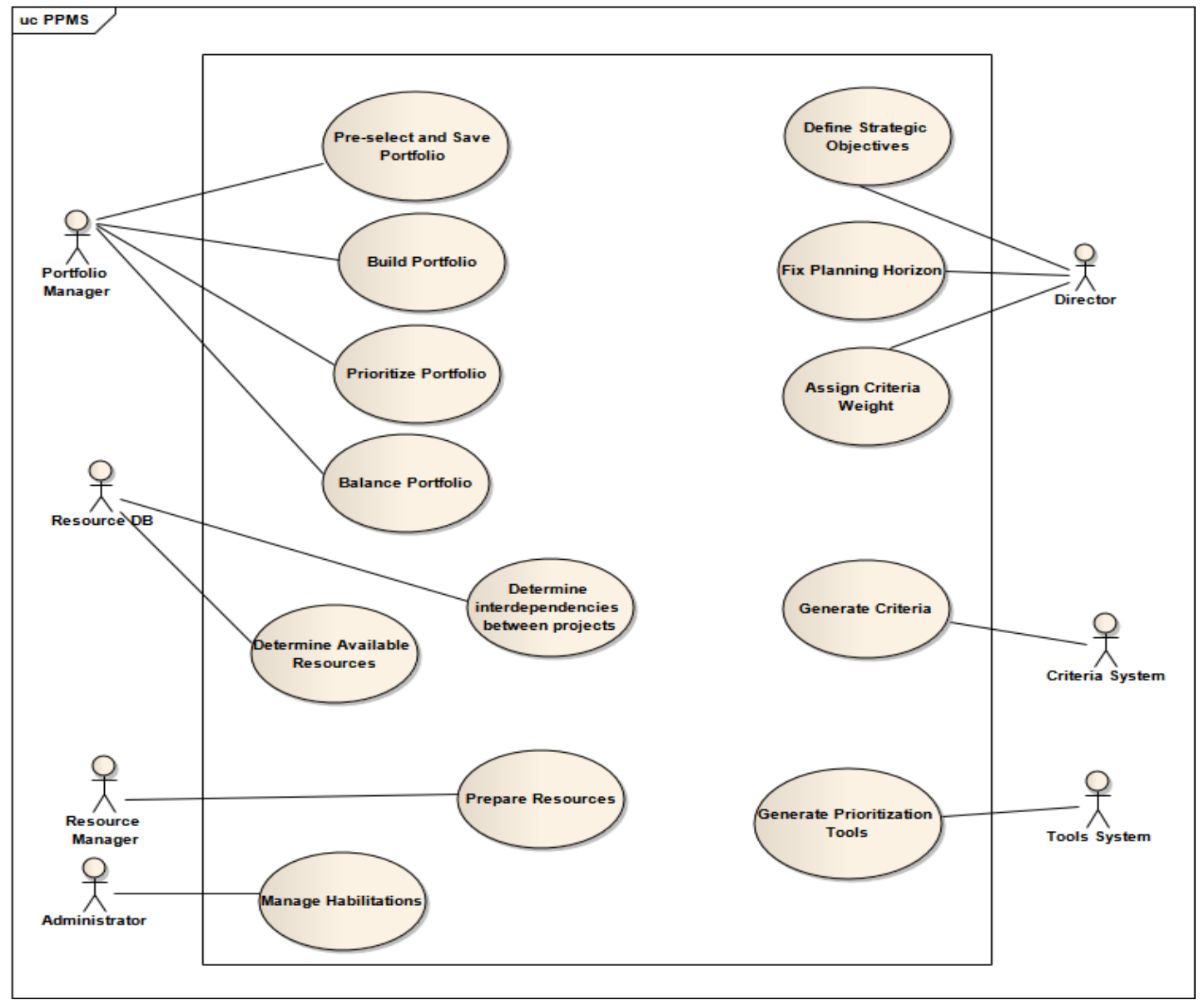

Figure 2. PPMS Use cases diagram

The class diagram represents classes constituting the system and the associations between them. It expresses in a general way the system's static structure. According to our study explained in the paragraph called "functional requirements", we have been able to identify the main classes shown in Figure 3. This diagram represents project portfolio prioritization and optimization in an organization by integrating two systems: one generates project performance criteria, while the other generates prioritization methods (numeric and nonnumeric). After prioritization stage comes resource optimization stage required to execute projects, using the company's database management system. The diagram contains 15 classes as described below:

The class named "user" contains user information system, determined by a login and other information relating to his identity. Once authenticated, he's associated with one or more roles. A user can be a project portfolio manager. This class thus makes it possible to identify the staff which interacts with the system. The class called "role" contains the information about all roles assigned to a user. Each role is determined by an identifier and a name. It's possible to know if a specific role is owned by one or more users. The class "PortfolioManager" collects data on the portfolio manager nature. A portfolio manager is represented by registration number and department. Usually, this representation depends on the structure and organization adopted by the company. The manager can also be a team attached to the PMO. The class named "portfolio" represents the organization's decision making unit. It gathers the data relating to the portfolio identification. Several portfolios can be managed by a portfolio manager. The class "project" collects data on projects making up the portfolio. A project is determined by an identifier, a start date, an end date, and a label. The class called "evaluation" is characterized by a project evaluation date and a score calculated by taking into account one or more criteria. Project evaluation is usually the responsibility of the evaluation committee, which is represented by officials from different levels of decision-making. The class "planification" is characterized by a date and rank of prioritization according to the prioritization method used. The system is flexible in such a way as to give decision-makers the opportunity to choose the appropriate method. The class "criteria" is associated with a type and a weight. The criteria are both qualitative and quantitative. The class "resource" contains information about available resources that will be 
allocated to projects. Each resource belongs to a category and has a capacity not to exceed.

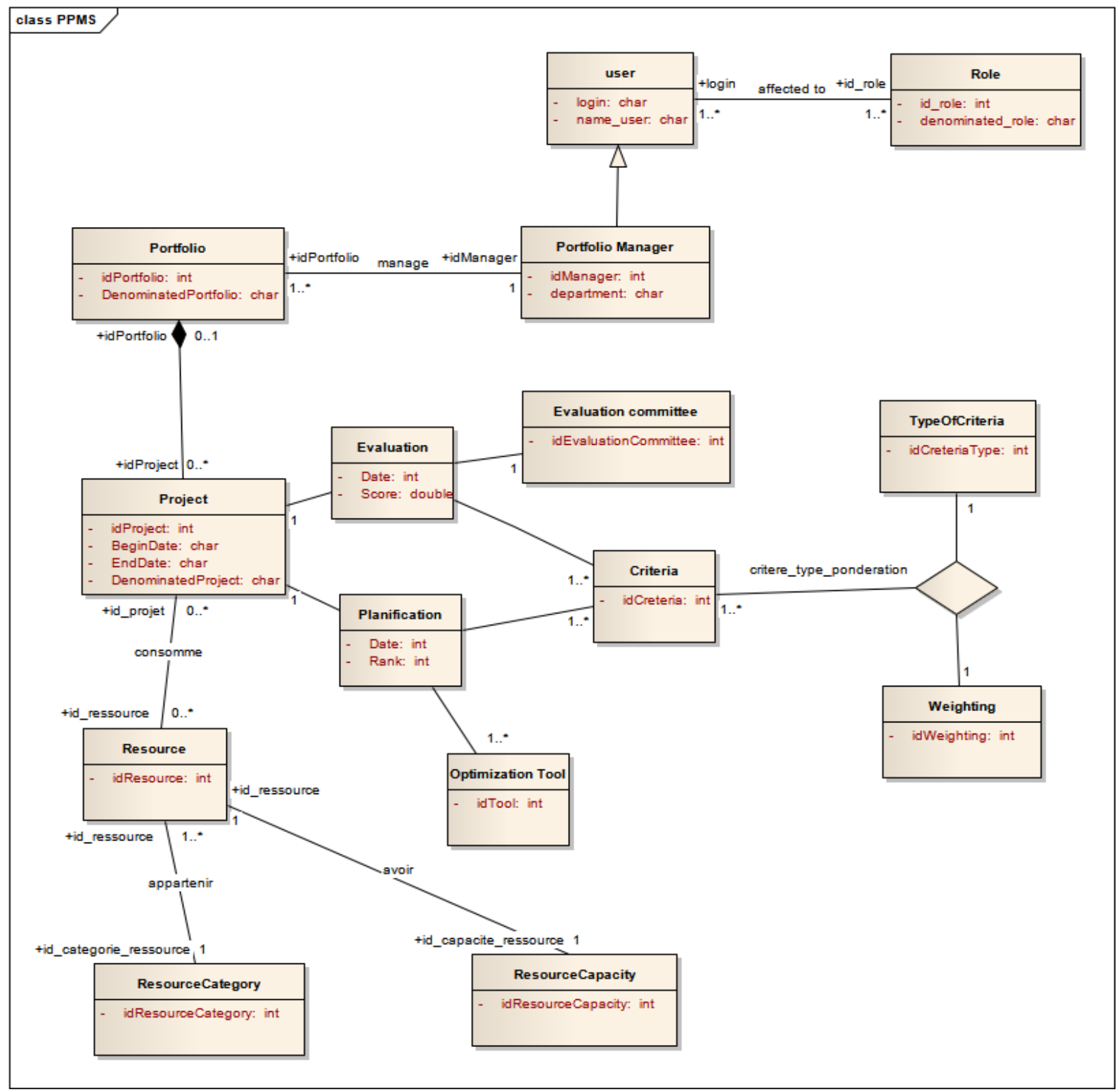

Figure 3. PPMS analysis classes' diagram

The activity diagram is a behavioral diagram of UML, making it possible to represent the triggering of events according to the states of the system and to model parallelizable behaviors. It is also used to describe a workflow. An activity diagram can be used to model an interactive process, global or partial, for a given system. It is advisable to express a temporal dimension on a part of the model, from diagrams of classes or use cases. From the study above, we have been able to identify the activity diagram shown in Figure 4 of the project portfolio prioritization system. 


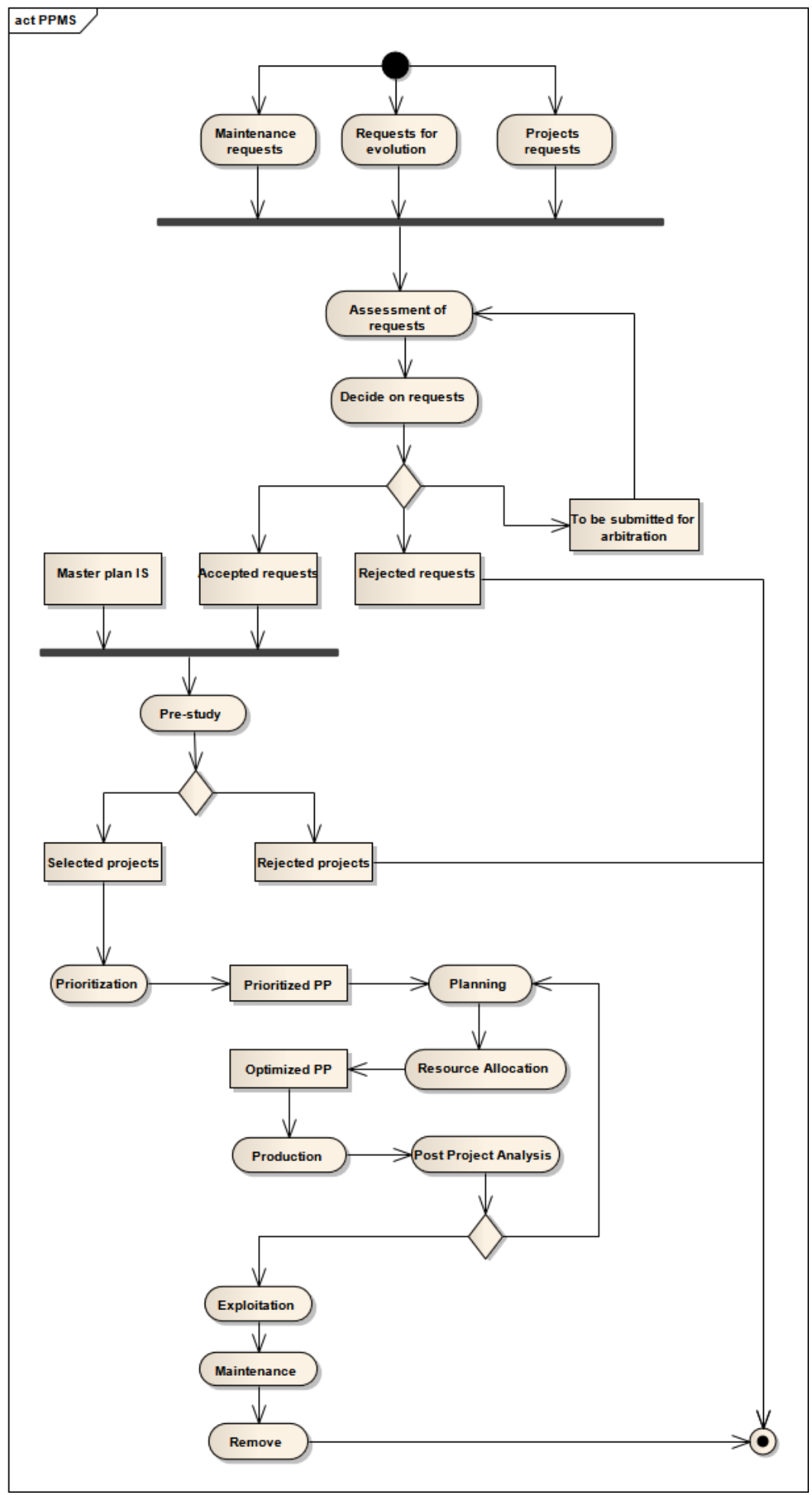

Figure 4. PPMS Activity diagram

In short, our proposed PPMS allow involving the various stakeholders in the whole levels of the organization such as: Portfolio Manager, Resource Manager, Director, Resource Databases, Generator of prioritization tools and criteria generator. Furthermore, it takes into consideration both the qualitative and quantitative criteria which are defined by the evaluation committee. The prioritization methods are too taking into account and they are flexible to choice. These methods are then numeric and non-numeric. All kinds of resources among others are considered since human, capital and equipment. They are everything integrated and managed by the database management system. Our model supported by a process that contains several steps such as: portfolio 
identification, portfolio pre-screening, portfolio study, portfolio screening, portfolio double prioritization, portfolio execution and portfolio performance. So, our PPMS is designed by general framework called PPMSP and described by classes diagram, use cases diagram and activity diagram. Finally, our model takes into account concomitantly the internal and external enterprise's environment.

\section{PPMS Implementation}

We developed a prototype for PPMS as a part of an ongoing research study whose aim is to improve project portfolio management practices at organizations. This PPMS is oriented to solve the problem related to the evaluation and the Planification phases by involving a set of functionalities that cover all the steps found in the PPMSP. The design of our prototype is focused on the individual project evaluation and portfolio selection phases of the PPMSP that covers the generating of the feasible solutions and allows the users to perform different scenario assessment by changing constraints and parameters. The PPMS implements the following components: information entropy algorithm for prioritizing project, branch and bound concept for generating possible portfolios, and mathematical programming for selecting a best portfolio. The software is a client server application developed in java language (Java Development Kit Library: JDK 1.8) in accordance with the Model View Controller (MVC) architecture. The persistence of the data is based on the integration between Java Persistence API (Application Programming Interface) and SQLite database. The source code of the current version of this implementation is available in the Github website ${ }^{1}$. Then, our prototype was designed to offer the following features:

- User accounts and roles management: the PPMS implements an authentication system and a classification of users into distinct roles to access the system functionalities. Figure 5 shows the login interface. Once logged in, the user is redirected to the home screen page.

- Portfolio and project management: it include such as the defining of criteria, the exporting of portfolio selection results to a PDF (Portable Document Format) file, and the Create, Retrieve, Update and Delete (CRUD) operations over projects and portfolios.

- Portfolio prioritization and optimization: it consists of a double prioritization step as seen in Figure 6.

- Portfolio comparison: it consists for comparing and presenting two or more portfolios to decision makers who can choice the best and optimal portfolio.

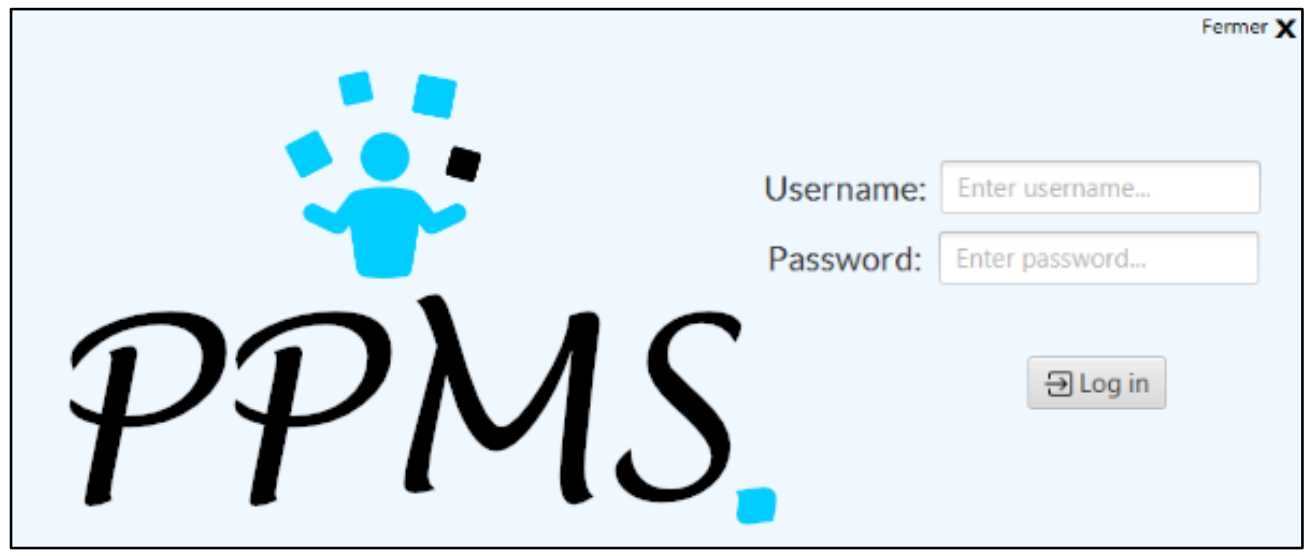

Figure 5. Login interface of PPMS

The technologies used in the development of the PPMS are all from Oracle suite. All source code was developed using Java API. There are three layers for PPMS architecture: The data layer is supported on database engine; the business layer contains the implementation of all classes with its attributes and methods (ensuring data processing and data access), and; the Graphical User Interface (GUI) is implemented with html pages over JavaFX. The developed PPMS has been implemented in web environment using open source programming language and Database Management System (DBMS).

\footnotetext{
${ }^{1}$ https://github.com/INPT-SEEDS/PPMS
} 


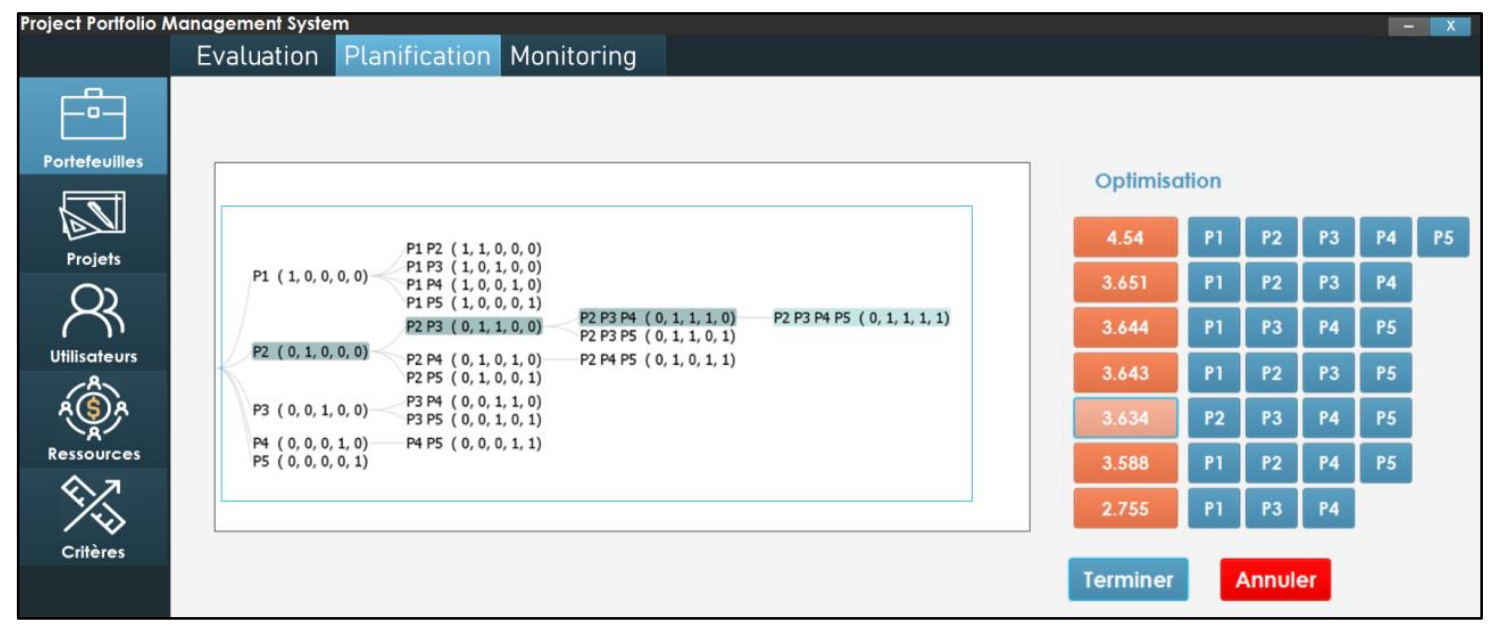

Figure 6. Planification page of PPMS

\section{Conclusions and Discussion}

Project Portfolio Management (PPM) has been considered as the bridge between enterprise strategic management and project management. One of the most important objectives of PPM is to choose the right projects and portfolios. The design of the Decision Support System through PPMS focuses on project prioritization and choosing the right projects from the many opportunities the organizations face.

To achieve success in implementing their strategy, public or private organizations need to know how to manage their resources effectively while overcoming their current challenges. The scarcity of resources obliges organizations to formally and rationally prioritize their project portfolios, in line with their organization's strategy, to ensure the achievement of objectives and the creation of value for their stakeholders. This value can take the form of economic return, sustainability, market share or even social visibility. This can only be achieved if the organizations set up a prioritization system that will be shared by all stakeholders.

In this paper, we have presented our formal modeling of the PPMS based on double prioritization steps. It can be integrated with applications in the organization and web services provided by business partners in the whole architecture. This prioritization system can assist senior management to prioritize portfolios and projects that represent the best alignment to strategic and operational drivers, with the least risk of achievement. This system takes a list of potential portfolios and projects and assesses each to identify the optimum portfolio, acknowledging organizational and resource constraints such as availability of investment funds and different resources. It assesses then two components of the potential project portfolio: first, the ideas and level to alignment to strategy, including returns on investment and size in terms of total cost. Second, the organization's execution capability should manage and deliver the project portfolio outcomes. We have also validated the PPMS with an implementation of the prototype containing a set of functionalities that cover all steps in the PPMSP.

To enable this system in the organizations to occur, it is necessary to collect key information about projects proposals. This is usually undertaken using a project portfolio assessment and prioritization form, which has two goals: On the one hand, allowing business operations to register an idea for investment evaluation and to make a potential funding decision through governance arrangements. On the other hand, the collecting enough information for assessing the proposals under prioritization model can made before starting the important work.

Project portfolio prioritization is an effective approach for optimizing and rationalizing project management, but it is not sufficiently exploited.One of the most important reasons that hamper this approach into practice is the project management system, which usually focuses on the operational aspects of project management without taking into account portfolio management as a whole. In this work, we set up a PPMS development framework based on the MDD whose objective is double:

- Provide the necessary tools for the implementation of such an adaptable system to the needs of each company. MDD frameworks are widely used for their ability to enable custom development, based on this metamodel, with less effort and cost.

- Implement a double prioritization step process: 
- Pre-selection of projects that can compose theproject portfolio based mainly on strategic and financial criteria.

- Final selection of the optimal portfolio mix based on optimizing the allocation of resources to the portfolio, once the visibility of available resources is more concise. This second phase is justified by the fact that information on resources is often available late compared to the deadline for the periodic creation and validation of the portfolio.

This work can be completed along several areas of improvement, namely:

- Setting up an implementation for a given context of a company (proof of concept)

Extension of the portfolio development framework to integrate concepts and packages oriented towards project management in general and not only portfolio prioritization management.

\section{Acknowledgments}

The authors thank the management of the doctoral school "CEDOC 2TI" of the National Institute of Posts and Telecommunications for the efforts made for the benefit of PhD students. Not forgetting to pay tribute to the teaching staff within the «SEEDS» team who, through their orientations, has achieved this work. In addition, the authors gratefully acknowledge the engineering students for the development of the PPMS prototype.

\section{References}

Ahlemann, F., \& Backhaus, K. (2006). Project management software systems - requirements, selection processes and products. Würzburg: BARC.

Archer, N., \& Ghasemzadeh, F. (2004). Project portfolio selection and management, In P. W. G. Morris \& J. K. Pinto (Eds.). The Wiley guide to managing projects, 237-255. Hoboken, NJ: John Wiley \& Sons.

Arisa, S., Ioanna, C., \& Kristian, K. (2015). The interplay between evidence and judgment in the IT project prioritization process. Journal of Strategic Information Systems. https:// doi.org/10.1016/j.jsis.2015.06.001

Augustin, P., \& Constanta-Nicoleta, B. (2014). Project Prioritization and Portfolio Performance Measurement in Project Oriented Organizations. Procedia - Social and Behavioral Sciences 119(2014), 339-348. https://doi.org/10.1016/j.sbspro.2014.03.039

Bible, M. J., Bivins, S., \& Bivins, S. S. (2011). Mastering Project Portfolio Management: A Systems Approach to Achieving Strategic Objectives. J Ross Press Series, ISBN: 9781604270662, https://books.google.co.ma/books?id=8B-XmtUKOWMC

Blocher, E., Stout, D., \& Cokins, G. (2010). Cost management: A strategic emphasis. (5th Ed.). New York, NY: McGraw-Hill Irwin.

Caballero, H. C., \& Schmidt, E. K. (2014). Decision support system for portfolio components selection and prioritizing. paper presented at PMI ${ }^{\circledR}$ Global Congress 2014-North America, Phoenix, AZ. Newtown Square, PA: Project Management Institute.

Chang, C. K., Christensen, M. J., \& Zhang, T., (2001). Genetic algorithms for project management. Ann Software Eng, 11(1), 107-139. https://doi.org/10.1023/A:1012543203763

Christelle, S. (2011). Guiding Global Software Development Projects using Scrum and Agile with Quality Assurance. 24th IEEE-CS Conference on Software Engineering Education and Training, ISBN: 978-1-4577-0349-2, 274 - 283. https://doi.org/10.1109/CSEET.2011.5876097

Christiane, G., von W., Jean, C. R. H., \& Aldo, von W. (2009). Enhancing Open Source Software in Alignment with CMMI-DEV. IEEE Software, 26(2), 59-67. https://doi.org/10.1109/MS.2009.34

Chrusciel, D., \& Field, D. W. (2006). Success Factors in Dealing with Significant Change in an Organization. Business Process Management Journal, 12, 503-516. https://doi.org/10.1108/14637150610678096

Cooper, C. L., Dewe, P., \& O’Driscoll (2001), Organizational Stress: A review and critique of theory, research, and applications. Thousand Oaks: Sage: 2001. https://doi.org/10.4135/9781452231235

Demetrios, S., Yannis, C., \& Dimitris, A. (2010). A Goal Oriented and Knowledge Based e-Government Project Management Platform. IEEE 43rd Hawaii International Conference on System Sciences (HICSS), ISBN: 978-1-4244-5509-6, 1-13. https://doi.org/10.1109/HICSS.2010.15 
Dorndorf, U., Pesch, E., \& Phan-Huy, T. (2000). Time-oriented branch-and bound algorithm for resource-constrained project scheduling with generalised precedence constraints. Manage Sci, 46(10), $1365-1384$.

Driss, E. H., Rabia, M., \& Mohamed, D. (2018). An Optimal Portfolio Selection based on a Hybrid Approach to improve Projects Oriented Organizations. Journal of Computer Science 2018, 14(11), 1454-1464. https://doi.org/10.3844/jcssp.2018.1454.1464

Driss, E. H., Rabia, M., \& Mohammed, D. (2016a). Project portfolio management, Towards a new project prioritization process. The 2nd Interna-tional Conference on Information Technology for Organizations Development (IT4OD), No Of Pages 8, Copyright: 978-1-4673-7689-1/16/\$31.00 O2016 IEEE. https://doi.org/10.1109/IT4OD.2016.7479281

Driss, E. H., Rabia, M., \& Mohammed, D. (2016b). Project Portfolio Management Information Systems (PPMIS): Information Entropy Based Ap-proch to Prioritize PPMIS. The 4th ieee international colloquium on information science and technology (CIST), No Of Pages 7, Copyright: 978-1-5090-0751-6/16/ @2016 IEEE. https://doi.org/10.1109/CIST.2016.7805048

Englund, R. L., \& Graham, R. J. (1999). From Experience: Linking Projects to Strategy. Journal of Production and Innovation Management, 16, 52-64.

Frederik, A. (2009). Towards a conceptual reference model for project management information systems. International Journal of Project Management, 27(2009), 19-30. https://doi.org/10.1016/j.ijproman.2008.01.008

Ghasemzadeh, F., \& Archer, N. P. (2000). Project portfolio selection through decision support. Decision Support Systems, 29(1), 73-88.

Graham, R. J., \& Englund, R. L. (2013). Creating an environment for successful projects. John Wiley \& Sons.

Hartmann, S. A. (2002). self-adapting genetic algorithm for project scheduling under resource constraints. Naval Res Logist, 49(5), 433-448.

Hasliza, M. S., Tengku, P. S. A., \& Azuraini, A. B. (2011). Using JIRA and Redmine in Requirement Development for Agile Methodology. IEEE 5th Malaysian Conference in Software Engineering (MYSEC), ISBN: 978-1-4577-1530-3, 408 - 413.

Hevner, A. R., March, S. T., Park, J., \& Ram, S. (2004). Design science in information systems research. MIS Quart 2004, 28(1), 75-105.

ISO 21504, (2015). Project, program and portfolio management - Guidance on portfolio management. British Standards Publication.

Jehad, A. D. (2011). Measuring the Discriminative Power of Object-Oriented Class Cohesion Metrics. IEEE TRANSACTIONS ON SOFTWARE ENGINEERING, 37(6), 788-804.

Jian WEN (2010). The Strategy-Oriented Project Portfolio Selection and Management. Proceeding in IEEE, copyright: 978-1-4244-7161-4/10/\$26.00 @2010 IEEE, https://doi.org/10.1109/ICEEE.2010.5660739

Juan, M. D., \& et al., (2011). Open linked data model revelation and access for analytical web science. SpringerVolume 240, ISBN: 978-3-642-24730-9, 105 - 116. https://doi.org/10.1007/978-3-642-24731-6_10

Kendall, G. I., \& Rollins, S. C. (2003). Advanced Project Portfolio Management and the PMO, Multiplying ROI at Warp Speed. Boca Raton, FL: J. Ross Publishing, Inc.

Kurbel, K. (1994). Groupware extension for a software - project management system. International Journal of Project Management, 12(4), 222-9. https://doi.org/10.1016/0263-7863(94)90046-9

Lu, L. L., Chiu, S. Y., \& Cox, L. A. (1999). Optimal Project Selection: Stochastic Knapsack with Finite Time Horizon. The Journal of the Operational Research Society, 50, 645-650. https://doi.org/10.1057/palgrave.jors.2600721

Luyin Zhao, Fadi, P. D., \& James, A. M. (2010). "Exploratory inspection a user-based learning method for improving open source software usability. Journal of Software Maintenance and Evolution, 22(8), 653-675. https://doi.org/10.1002/smr.455

Mantel, S. J., Meredith, J. R., Shafer, S. M., \& Sutton, M. M. (2011). Project management in practice (4th ed.). Hoboken, NJ: John Wiley \& Sons.

Muhammad, S., \& Muhammad, S. (2016). Software Project Management: Tools assessment, Comparison and 
suggestions for future development. International Journal of Computer Science and Network Security, 16(1), 31-42.

Object Management G. (2005). Unified modelling language: superstructure. Verson 2.0, Object Management Group.

Ou Liu, Jun Wang, Jian Mac, \& Yonghong Sun (2016). An intelligent decision support approach for reviewer assignment in $R \& D$ project selection. Computers in Industry 76(2016), 1-10. https://doi.org/10.1016/j.compind.2015.11.001

PMBOK® Guide Sixth Edition. (2017). A Guide to the Project Management Body of Knowledge. Project Management Institute (PMI).

Project Management Institute. (2012). The standard for portfolio management - third edition, Newtown Square, PA: Project Management Institute.

Project Management Institute. PMI (2013). The Standard of Portfolio Management. 3.ed. Project Management Institute, Inc. Newtown Square - PA.

Rădulescu, Z., \& Rădulescu, M. (2001). Project Portfolio Selection Models and Decision Support. Romania: Research Paper, National Institute for Research \& Development in Informatics.

Ricardo, S., Jorge, G., \& Mario, R. (2017). Projects Selection and Prioritization: A Portuguese Navy pilot model. Procedia Computer Science, CENTERIS 2017 - International Conference on ENTERprise Information Systems / ProjMAN 2017 - International Conference on Project MANagement / HCist 2017 - International Conference on Health and Social Care Information Systems and Technologies, CENTERIS/ProjMAN/HCist 2017, 121, 72-79. https://doi.org/10.1016/j.procs.2017.11.011

Romeo, G. M., \& Marivic, V. M. (2010). Comparing Project Prioritization Method and Net Present Value Method of Capital Rationing Using Kendall's Tau Distance. Proceedings of the 2010 IEEE ICMIT, 978-1-4244-6567-5/10/\$26.00 @2010 IEEE 95. https://doi.org/10.1109/ICMIT.2010.5492833

Saaty, T. L. (2008). Decision making with the analytic hierarchy process. International Journal of Services Sciences, 1(1), 83-98.

Schulz, R., Malzahn, U., \& von Schoultz, F. (1996). An integrated project management information system. Leipzig.

Voss, M. (2012). Impact of customer integration on project portfolio management and its success-developing a conceptual framework. International Journal of Project Management, 30, 567581. https://doi.org/10.1016/j.ijproman.2012.01.017

Walker, H. J., Armenakis, A. A., \& Bernerth, J. B. (2007). Factors influencing organizational change efforts: An integrative investigation of change content, context, process and individual differences. Journal of Organizational Change Management, 20, 761- 773. https://doi.org/10.1108/09534810710831000

White, D., \& Fortune, K. (2002). Current practice in project management - an empirical study. International Journal of Project Management, 20(1), 7.

Winter, R., \& Schelp, J. (2006). Reference modeling and method construction: a design science perspective. In: Proceedings of the 2006 ACMsymposium on applied computing, Dijon, France. ACM Press; 2006. 1561-1562. https://doi.org/10.1145/1141277.1141638

Yelin, K. C. (2005). Linking Strategy and Project Portfolio Management. In Levine, H. A. (eds.) (2005) Project Portfolio Management: A practical guide to selecting projects, managing portfolios and maximizing benefit, 137- 145. USA: Pfeiffer Wiley.

\section{Copyrights}

Copyright for this article is retained by the author(s), with first publication rights granted to the journal.

This is an open-access article distributed under the terms and conditions of the Creative Commons Attribution license (http://creativecommons.org/licenses/by/4.0/). 